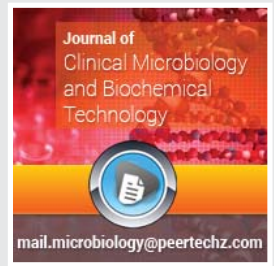

\title{
COVID-19 and Kingdom of Saudi Arabia
}

\section{Saleh A Eifan* and Atif Hanif}

Department of Botany and Microbiology, College of Science, King Saud University, Riyadh, Saudi

Received: 01 April, 2020

Accepted: 08 April, 2020

Published: 09 April, 2020

*Corresponding author: Saleh A. Eifan, Department of Botany and Microbiology, College of Science, King Saud University, Riyadh, Saudi Arabia, Tel: 00966550696975; Email: seifan@KSU.EDU.SA; saifan4@hotmail.com

https://www.peertechz.com

\section{Check for updates} Arabia

The novel coronavirus disease originated from the Hubei Province of China in December 2019 [1]. The spread of infection is continuous across the world. Previously different human corona viruses like $\mathrm{HCoV}-229 \mathrm{E}, \mathrm{HCoV}-\mathrm{OC} 43, \mathrm{HCoV}-\mathrm{NL} 63$ and HCoVHKU1 of animal origin (BAT) were known to cause respiratory illnesses in humans. Coronaviruses are known to cause intestinal and respiratory illnesses in animals and humans. These viruses are enveloped positive sense single stranded nonsegmented RNA viruses known to infect different types animals and humans. The virus genome size ranges between $26 \mathrm{~kb}$ to $32 \mathrm{~kb}$. Seven types are known to cause human diseases, among them alpha corona viruses can cause mild or asymptomatic illnesses while beta corona viruses my cause fatal and sever infections. Human coronaviruses like Severe Acute Respiratory Syndrome Coronavirus (SARS-CoV), Middle East Respiratory Syndrome Cronavirus (MERS-CoV), and Coronavirus Disease 2019 (COVID-19) are known as pathogens of zoonotic origin and basically originated from wild animals [2]. SARS-CoV-2 genome has shown $96 \%$ similarity with bat corona viruses. Genome size of corona viruses is exceptionally long (up to $32 \mathrm{~kb}$ ) among RNA viruses and partially mediated by an increased replication fidelity. Mutation rate in corona viruses greatly depending on virus adaption to different or new hosts. These viruses are also known to show high fidelity replication [3] (Table 1).

Table 1: Comparison of SARS-CoV, MERS-CoV and SARS-CoV-2 Characteristics.

\begin{tabular}{|c|c|c|c|}
\hline Comparison criteria & SARS-CoV & MERS-CoV & SARS-CoV-2 \\
\hline Genus & Betacoronavirus lineage $B$ & Betacoronavirus lineage $\mathrm{C}$ & Betacoronavirus lineage B \\
\hline Re-emergence country & 2002 Guangdong,China & 2012 Arabian Peninsula & 2019 Wuhan, China \\
\hline Reservoir & Bat & Bat & Bat \\
\hline Probable Intermediate host & civet cats & camel & (snakes, civet cats, pangolin) \\
\hline Genome length (bp) & 29,741 & 30,119 & 29,903 \\
\hline Transmission from patient via & Respiratory Droplet, Faecal-oral & Respiratory Droplet, Faecal-oral & Respiratory Droplet, Personal contacts \\
\hline Infection occur & After sever symptoms & After sever symptoms & $80 \%$ asymptotic \\
\hline Case-fatality rate & $9.60 \%$ & $34.4 \%$ & $5.6 \%$ till $07 / 04 / 20$ \\
\hline RO & $2.0-4.0$ & 3.0 & 2.5 till 07/04/20 \\
\hline Distribution countries and territories & 29 & 26 & 209 till 03/03/20 \\
\hline Total cases/deaths & $8,096 / 774$ & $2506 / 862$ & $\begin{array}{c}1,361,538 / 76,315 \\
\text { till } 07 / 04 / 20\end{array}$ \\
\hline Cellular receptor & ACE2 & DDP4 & ACE2 \\
\hline Tissue tropism & Lower respiratory & Lower respiratory & Lower respiratory \\
\hline Incubation average & $1-4$ & $2-14$ & $3-7$ \\
\hline Susceptible people & Young adult & Elderly over 49 & all \\
\hline Disease & Severe acute respiratory syndrome & Middle East respiratory syndrome & Covid 19 \\
\hline
\end{tabular}


Four main structural genes of corona viruses are known as nucleocapsid protein (N), Small Membrane protein (SM), spike protein (S) and membrane glycoprotein (M). Evolution of different accessory proteins play an important role in adaptation of virus to the new host and also involve in increase of pathogenicity. Evolutionary history of corona viruses indicate the ability of these viruses for host jumps and adaption is tormenting and should be considered carefully to determine the future strategies for prevention and control of future outbreaks. Mutation in spike protein and nucleocapsid protein are important for conferring stability and adaptability of the virus. S proteins play a vital role in attachment to the host cell receptor and fusion of membrane. $\mathrm{N}$ protein is involved in viral transcription and assembly. So, their role is important in viral infection and pathogenesis [4]. Evolutionary history of corona viruses indicate that they depict high plasticity with in their genome contents and recombination. Homologous recombination has been described in SARS-CoV-2 spike glycoprotein that may favor the cross species transmission of the virus [5].

In COVID-19 Higher efficiency of human to human transfer and relatively lower pathogenicity as compare to previous SARS-COV outbreak is an indicator of stable mutations in these proteins. Due to the positive selection pressure the virus may evolve toward higher pathogenicity and more efficient human to human transfer. Homologues recombination has also been observed in S protein of SARS-CoV-2 causative agents should be considered as possible indicator of cross species transmission of the virus [6].

MERS-CoV spread in Middle East caused 858 deaths out of 2494 laboratory confirmed cases has been notified by World Health Organization (WHO). A total of 827 deaths out of 2131 laboratory confirmed cases has been reported from Kingdom of Saudi Arabia. Currently MERS-CoV cases are reported weekly in Kingdom of Saudi Arabia and a trend of reduction in transmission has been recorded [7]. In gulf region 5700 confirmed cases of COVID-19 has been recorded out of which Kingdom of Saudi Arabia has reported onset of 2752 cases with 551 recoveries and 38 deaths [8].

The appearance and wide spread of COVID-19 cases in Kingdom of Saudi Arabia may lead to increase possibilities of these viruses recombination and mutation result in emergence of novel coronaviruses. Previously corona viruses were considered as mild pathogens to cause infection in immunocompetent individuals. The outbreak of SARS-COV in 2002 in China and MERs CoV in Saudi Arabia in 2012 was caused by highly pathogenic corona viruses. SARS-CoV, SARS-CoV-2 use angiotensin-converting enzyme 2 (ACE2) and MERS-CoV use dipeptidyl peptidase 4 (DPP4) receptors for attachment and infection of the cells $[9,10]$. These three types of viruses are reported to be transmitted to humans by direct contact of animals and later human to human transfer was established. MERS-CoV is already circulating in animal and human reservoirs in Kingdom of Saudi Arabia. SARS-CoV-2 emergence in the country may have a serious impact on genetic diversity, interspecies transmission of these viruses especially with the reference to the mutation and recombination probabilities of coronaviruses. The information presented in article can play an effective role to adopt strategy for preparation and prevention of future corona virus outbreaks.

\section{References}

1. Chan JF-W, Yuan S, Kok K-H (2020) A familial cluster of pneumonia associated with the 2019 novel coronavirus indicating person-to person transmission: A study of a family cluster. Lancet 395: 514-523. Link: https://bit.ly/3e6GFbA

2. Drosten C, Günther S, Preiser W (2003) Identification of a novel coronavirus associated with severe acute respiratory syndrome. N Engl J Med 348: 1967-1976. Link: https://bit.ly/2UUPcXG

3. Chen Y, Liu Q, Guo D (2020) Emerging coronaviruses: genome structure, replication, and pathogenesis. J Med Virol 92: 418-423. Link: https://bit.ly/2UVxYJR

4. Su S, Wong G, Shi W (2016) Epidemiology, genetic recombination, and pathogenesis of coronaviruses. Trends Microbiol 24: 490-502. Link: https://bit.ly/2RDXTUr

5. Ji W, Wang W, Zhao X, Zai J, Li X (2020) Homologous recombination within the spike glycoprotein of the newly identified coronavirus may boost cross-species transmission from snake to human. J Med Virol 92. Link: https://bit.ly/2UVxVxF

6. Zhao X, Zai J, Li X (2020) Homologous recombination within the spike glycoprotein of the newly identified coronavirus may boost crossspecies transmission from snake to human. J Med Virol 92. Link: https://bit.ly/2UVxVxF

7. Ministry of Health $(\mathrm{MOH})(2020)$ Command and Control Center. Nationa Public Health Events, 2020. Ministry of Health Link: https://bit.ly/34ugqrq

8. Ministry of Health (MOH) (2020) Command and Control Center. National Public Health Events. Link: https://bit.ly/2Vf9J8f

9. Li, WH (2003) Angiotensin- converting enzyme 2 is a functional receptor for the SARS coronavirus. Nature 426: 450-454. Link: https://bit.ly/2XmKpQA

10. Lu G (2013) Molecular basis of binding between novel human coronavirus MERS-CoV and its receptor CD26. Nature 500: 227-231. Link: https://bit.ly/2Va3NOi 